\title{
Cross-Border Shopping and the Atkinson-Stiglitz Theorem
}

\section{Sebastian G. Kessing* $\quad$ Bernhard Koldert ${ }^{\dagger}$}

\begin{abstract}
We introduce cross-border shopping and indirect tax competition into a model of optimal taxation. The Atkinson-Stiglitz result that indirect taxation cannot improve the efficiency of information-constrained tax-transfer policies, and that indirect taxes should not be differentiated across goods, is shown to hold in this case. This result is derived for symmetric as well as for asymmetric countries. However, if the tax system must contain elements of indirect taxation, differentiated indirect tax rates arise in the equilibrium and restricting differentiated indirect taxation can be welfare-increasing.
\end{abstract}

JEL classification: H21, F15,

Keywords: Cross-border shopping, Atkinson-Stiglitz theorem, tax competition, direct and indirect taxes,

\footnotetext{
${ }^{*}$ University of Siegen

${ }^{\dagger}$ University of Siegen; Corresponding author, University of Siegen, Department of Economics, Hölderlinstrasse 3, 57076 Siegen, Germany. Phone: +49-271-740-3152; Fax: +49271-740-2732; E-mail: koldert@vwl.wiwi.uni-siegen.de
} 


\section{Introduction}

The completion of the single European Market in the early 1990s removed the barriers to cross-border shopping but left the right to set indirect taxes mostly at the level of the individual Member States. As a consequence, economists have extensively studied tax competition in indirect taxes for cross-border shoppers from a theoretical perspective, cf. Kanbur and Keen (1993), Nielsen (2001, 2002), as well as empirically, cf. Lockwood and Magali (2009), Asplund et al. (2007), Devereux et al. (2007), Jacobs et al. (2010), and Agrawal (2011), among others. However, while these studies have largely enriched our understanding of indirect tax competition, and have found support for its empirical relevance, they have not shed much light on its consequences for other aspects of the tax system, such as the interplay between direct and indirect taxes.

The present study considers the implications of cross-border shopping for optimal direct taxation and governments' capabilities to implement incentivecompatible redistributive taxation. More specifically, we investigate the role of cross-border shopping for the validity of the Atkinson-Stiglitz theorem. In their seminal contribution, Atkinson and Stiglitz (1976), henceforth AS, showed that commodity taxation cannot improve efficiency, if preferences are separable in labor and consumption, and the government implements an optimal non-linear direct taxation scheme. This result is compatible with any level of uniform commodity taxation in a closed economy setting, which makes the AS result one of the most policy relevant optimal taxation results, since it provides a theoretically sound argument for uniform commodity taxation. Accordingly, many scholars have scrutinized its scope and robustness. Naito (1999) showed that the result no longer applies, if wages are determined endogenously. Saez (2004), however, demonstrated that it can be restored if human capital formation is also made endogenous. Similarly, Cremer et 
al. (2001) have considered the implications of different wealth endowments, and Boadway and Pestieau (2003) analyze the robustness of the AS result to various other assumptions, such as differences in needs, different types of labor, or household production. Finally, Kaplow (2006), and Laroque (2005), have further extended the arguments in favor of uniform taxation showing that direct taxes must not necessarily be chosen optimally for the AS result to apply.

The existing literature has typically maintained the closed economy setting. Given the increasing market integration in Europe, and elsewhere, we depart from the closed economy assumption and analyze the implications of cross-border shopping and tax competition for the AS result. Our key research question is, whether the additional constraint of tax competition in indirect taxes for some products that are subject to cross-border shopping implies that a government, in its desire to implement an incentive-compatible tax-transfer policy, should rely on indirect taxation besides direct taxation, and whether indirect taxes should be differentiated between goods which are subject to cross-border shopping and those goods which are not. The analysis incorporates cross-border shopping into the framework of Boadway and Pestieau (2003), which itself is an extension of the Stiglitz' (1982) two-type optimal taxation model. Individuals are tied to their place of residence for work, but are mobile regarding the purchase of certain consumption goods. The approach turns the model into a strategic tax competition framework in which the governments try to redistribute subject to their information constraints, and compete for cross-border shoppers.

We derive a number of results. First, the AS result holds even with competition for cross-border shoppers. In general, indirect taxation is not needed to increase efficiency, so the argument for uniform indirect taxation remains valid. This result is independent of the nature of the competing countries. 
In particular, asymmetries regarding the relative size of the countries, the government's relative welfare weights, or differences in the skill distribution are not affecting its validity. This finding can be contrasted with the existing partial equilibrium models, such as Kanbur and Keen (1993) or Nielsen (2001) which find a direct link between country asymmetries and equilibrium policies. However, if countries rely on indirect taxation for exogenous reasons, uniform indirect taxation is no longer optimal from an individual country's perspective. If the exogenous positive rates on non-tradable goods are symmetric between countries, restricting differential indirect taxation is welfare increasing. Finally, if countries are asymmetric regarding the exogenous use of positive indirect taxes on non-tradable goods, uniform taxation is also not optimal from each country's individuals perspective. However, in this case, forcing countries to use uniform taxes, can make both countries worse off.

The results are directly relevant for the ongoing policy discussion on the European VAT system, in particular regarding the scope individual Member States should be granted to apply reduced or zero VAT rates, or VAT exemptions, cf. the European Commission's (2010) Green Paper on the future of the European VAT system. Our results suggest that, given the importance of indirect taxes, the scope and the size of deviations for those goods, that are particularly suited for cross-border shopping, should be limited, and negatively related to the degree of harmonization of standard rates.

Finally, our approach is complementary to other studies that have introduced aspects of tax competition into optimal taxation models. Huber (1999) considers the interaction between optimal income taxation and the taxation of internationally mobile capital. Simula and Trannoy (2010) and Lipatov and Weichenrieder (2010) introduce labor mobility into the optimal taxation framework and study the resulting changes to the optimal tax schedule. 


\section{The framework}

There are two countries $j=s, b$, with a mass of individuals in country $s$ (small) equal to $A_{s}$, and equal to $A_{b}$ in country $b$ (big), $A_{b} \geq A_{s}$. In both countries there are low and high productivity individuals $i=l, h$, who only differ in their productivity. Their relative shares are denoted by $\lambda_{j, i}$. Preferences are represented by the strictly concave utility function

$$
U_{j, i}=u\left(g\left(x_{j, i}, z_{j, i}\right), l_{j, i}\right),
$$

which is separable in the sub-utility of consumption $g(.,$.$) and labor l$. Gross income of an individual of productivity $i$ in country $j$ is denoted by $y_{j, i}$, and $y_{j, i}=l_{j, i} w_{j, i}$ where $w$ denotes the wage rate. The net income is denoted by $c_{j, i}$. There are two consumption goods, $x$ and $z$, with producer prices set to one. Both goods can be bought in the two countries at the consumer price

$$
q_{j, k}=1+t_{j, k}
$$

where $t_{j, k}$ is the specific tax levied on good $k=x, z$, in country $j$. Transport costs for good $x$ are prohibitively high, whereas good $z$ can be bought in the neighboring country subject to transport costs. We call $x$ the non-tradable and $z$ the tradable good. The cross-border shopping decision is modeled following Haufler (1996). Transport costs for good $z$ are quadratic in the volume of cross-border shopping. Denoting by $z_{j, i,-j}$ the quantity of good $z$ that is bought across the border, total transportation costs are $K\left(z_{j, i,-j}\right)=$ $\frac{a}{2} z_{j, i,-j}^{2}$, such that the relevant marginal transport costs are $a z_{j, i,-j}, a>0 .{ }^{1}$

Buying one more unit abroad will be preferred to shopping at home if the price abroad plus the marginal transport costs is less than the price in the country of residence, i.e., if $t_{-j, z}+a z_{j, i,-j}<t_{j, z}$. Note that the decision about whether, and how much, to buy abroad is the same for high and low

\footnotetext{
${ }^{1}$ Wholesale transportation costs are assumed to be zero.
} 
productivity individuals. Consequently, for given tax rates $t_{j, z}$ and $t_{-j, z}$, consumers are indifferent between buying at home or abroad at quantity

$$
z_{j, i,-j}^{*}=\frac{t_{j, z}-t_{-j, z}}{a} .
$$

Since cross-border shopping is restricted to positive amounts, we have $z_{j, i,-j} \equiv$ $\max \left[0, z_{j, i,-j}^{*}\right]$. By assumption, individuals always buy some amount of good $z$ in their home country, such that $z_{j, i,-j}<z_{j, i}$.

We focus on the welfare maximization problem of government $j$, noting that the other government $-j$ solves an analogous problem. It maximizes a Utilitarian welfare function with welfare weights $\alpha_{j, i}$

$$
W_{j}=\sum_{i=h, l} \alpha_{j, i} A_{j} \lambda_{j, i} u_{i}\left(f\left(q_{j, z}, q_{-j, z}, c_{j, i}\right), \frac{y_{j, i}}{w_{j, i}}\right),
$$

where utility has been rewritten using the indirect utility function $f($.$) . The$ government's budget is

$$
\begin{aligned}
0 \leq & \sum_{i=h, l} \lambda_{j, i}\left(y_{j, i}-c_{j, i}\right) A_{j} \\
& +\sum_{i=h, l} \lambda_{j, i} A_{j} t_{j, z}\left[z_{j, i}\left(q_{j, z}, q_{-j, z}, c_{j, i}\right)-z_{j, i,-j}\left(q_{j, z}, q_{-j, z}\right)\right] \\
& +\sum_{i=h, l} A_{-j} \lambda_{-j, i} t_{j, z} z_{-j, i, j}\left(q_{j, z}, q_{-j, z}\right) \\
& +\sum_{i=h, l} \lambda_{j, i} A_{j} t_{j, x} x_{j, i}\left(q_{j, z}, q_{-j, z}, c_{j, i}\right) \equiv B .
\end{aligned}
$$

The first term of the government budget consists of the direct taxes or subsidies paid by, or to, the low productivity and high productivity individuals, respectively. The second line are the tax revenues from the domestic purchases of the tradable good. The third line adds the taxes paid by the cross-border shoppers from the neighboring country. The fourth line are the revenues from the indirect taxes on $x$. 
The government's tax policy also has to be incentive-compatible. We consider downward incentive compatibility only. This condition is

$$
u_{h}\left(f\left(q_{j, z}, q_{-j, z}, c_{j, h}\right), \frac{y_{j, h}}{w_{j, h}}\right) \geq u_{h}\left(f\left(q_{j, z}, q_{-j, z}, c_{j, l}\right), \frac{y_{j, l}}{w_{j, h}}\right) .
$$

We also assume that the share of low productivity individuals is sufficiently large such that the optimal policy entails a positive labor supply from the low productivity types. Accordingly, the government's problem is to maximize (4) subject to (5) and (6) choosing $y_{j, l}, y_{j, h}, c_{j, l}, c_{j, h}$ and $q_{j, z}$ with the corresponding Lagrangean

$$
\begin{aligned}
\mathcal{L}= & \sum_{i=l, h} \alpha_{j, i} A_{j} \lambda_{j, i} u_{i}\left(f\left(q_{j, z}, q_{-j, z}, c_{j, i}\right), \frac{y_{j, i}}{w_{j, i}}\right) \\
& +\mu B+\gamma\left[u_{h}\left(f\left(q_{j, z}, q_{-j, z}, c_{j, h}\right), \frac{y_{j, h}}{w_{j, h}}\right)-u_{h}\left(f\left(q_{j, z}, q_{-j, z}, c_{j, l}\right), \frac{y_{j, l}}{w_{j, h}}\right)\right] .
\end{aligned}
$$

The first order conditions are

$$
\begin{gathered}
c_{j, l}: \alpha_{j, l} A_{j} \lambda_{j, l} \frac{\partial u_{l}}{\partial f} \frac{\partial f}{\partial c_{j, l}}-\mu \lambda_{j, l} A_{j}+\mu \lambda_{j, l} A_{j} t_{j, z} \frac{\partial z_{j, l}}{\partial c_{j, l}}+ \\
\mu \lambda_{j, l} A_{j} t_{j, x} \frac{\partial x_{j, l}}{\partial c_{j, l}}-\gamma \frac{\partial \hat{u}_{h}}{\partial f} \frac{\partial f}{\partial c_{j, l}}=0, \\
c_{j, h}: \alpha_{j, h} A_{j} \lambda_{j, h} \frac{\partial u_{h}}{\partial f} \frac{\partial f}{\partial c_{j, h}}-\mu \lambda_{j, h} A_{j}+\mu \lambda_{j, h} A_{j} t_{j, z} \frac{\partial z_{j, h}}{\partial c_{j, h}}+ \\
\mu \lambda_{j, h} A_{j} t_{j, x} \frac{\partial x_{j, h}}{\partial c_{j, h}}+\gamma \frac{\partial u_{h}}{\partial f} \frac{\partial f}{\partial c_{j, h}}=0,
\end{gathered}
$$




$$
\begin{aligned}
q_{j, z}: & \sum_{i=l, h} \alpha_{j, i} A_{j} \lambda_{j, i} \frac{\partial u_{i}}{\partial f} \frac{\partial f}{\partial q_{j, z}} \\
& +\mu A_{j}\left[t_{j, z} \sum_{i=l, h} \lambda_{j, i} \frac{\partial z_{j, i}}{\partial q_{j, z}}+\sum_{i=l, h} \lambda_{j, i}\left(z_{j, i}-z_{j, i,-j}\right)\right] \\
& -\mu A_{j} t_{j, z} \sum_{i=l, h} \lambda_{j, i} \frac{\partial z_{j, i,-j}}{\partial q_{j, z}}+\mu A_{j} t_{j, x} \sum_{i=l, h} \lambda_{j, i} \frac{\partial x_{j, i}}{\partial q_{j, z}} \\
& +\mu \sum_{i=l, h} A_{-j} \lambda_{-j, i} z_{-j, i, j}+\mu t_{j, z} \sum_{i=l, h} A_{-j} \lambda_{-j, i} \frac{\partial z_{-j, i, j}}{\partial q_{j, z}} \\
& +\gamma\left[\frac{\partial u_{h}}{\partial f} \frac{\partial f}{\partial q_{j, z}}-\frac{\partial \hat{u}_{h}}{\partial f} \frac{\partial f}{\partial q_{j, z}}\right]=0,
\end{aligned}
$$

and additional first order conditions with respect to $y_{j, l}, y_{j, h}, \mu$, and $\gamma$. These first order conditions implicitly define the best response to the neighboring country's tax policy and must be, together with their counterparts for the neighboring country $-j$, be fulfilled in equilibrium. To analyze the properties of the equilibrium we multiply (7) by $z_{j, l, j}$ and (8) by $z_{j, h, j}$ and add the resulting expressions to (9). After further manipulation this yields

$$
\begin{aligned}
0= & \sum_{i=l, h} A_{j} \lambda_{j, i} t_{j, z} \frac{\partial \tilde{z}_{j, i}}{\partial q_{j, z}}+\sum_{i=l, h} \lambda_{j, i} A_{j} t_{j, x} \frac{\partial \tilde{x}_{j, i}}{\partial q_{j, z}} \\
& -\sum_{i=l, h} A_{j} \lambda_{j, i} t_{j, z} \frac{\partial z_{j, i,-j}}{\partial q_{j, z}}+\sum_{i=l, h} A_{-j} \lambda_{-j, i} z_{-j, i, j}+\sum_{i=l, h} A_{-j} \lambda_{-j, i} t_{j, z} \frac{\partial z_{-j, i, j}}{\partial q_{j, z}} \equiv F_{j},
\end{aligned}
$$

where $\frac{\partial \tilde{z}_{j, i}}{\partial q_{j, z}}$ and $\frac{\partial \tilde{x}_{j, i}}{\partial q_{j, z}}$ are the derivatives of the compensated demand functions with respect to prices. This expression $F_{j}$ is at the heart of our further discussion of the potential equilibria. Note that for country $-j$ an analogous expression $F_{-j}$ must hold in the equilibrium.

\section{$3 \quad$ Symmetric countries}

Consider first the case of symmetric countries. As usual in the literature, we set the tax on good $x$ to zero in both countries, and also normalize the mass of 
individuals in both countries to unity. Thus, $A_{j}=A_{-j}=1, \alpha_{j, i}=\alpha_{-j, i}=\alpha_{i}$, $\lambda_{j, i}=\lambda_{-j, i}=\lambda_{i}, t_{j, x}=t_{-j, x}=0$. Note that with $t_{j, x}=0$ the second term of $F_{j}$ in (10) disappears. Moreover, in a symmetric equilibrium we have $t_{j, z}=t_{-j, z}=t_{z}$, and accordingly $z_{-j, i, j}=z_{j, i,-j}=0$ and $\frac{\partial z_{-j, i, j}}{\partial q_{j, z}}=\frac{\partial z_{j, i,-j}}{\partial q_{-j, z}}=0$. Expression (10) reduces to

$$
F_{j}=t_{z}\left[\lambda_{l} \frac{\partial \tilde{z}_{l}}{\partial q_{z}}+\lambda_{h} \frac{\partial \tilde{z}_{h}}{\partial q_{z}}-\frac{\lambda_{l}}{a}-\frac{\lambda_{h}}{a}\right]=0 .
$$

The term in parentheses is negative, such that the equilibrium must entail $t_{z}=t_{x}=0$. We summarize this result in our first proposition:

Proposition 1 If the two neighboring countries are symmetric, and both countries set the tax on the non-tradable good to zero, the symmetric tax policy equilibrium entails no tax on the tradable good in both countries.

Indirect taxation does not play a role in the efficient redistributive tax policy of the two countries competing for cross-border shoppers. Since both indirect tax rates are set to zero, indirect taxation is also uniform. Thus, in a symmetric world with cross-border shopping, the AS result holds.

\section{Asymmetric countries}

Consider next the case of asymmetric countries. We do not distinguish between the different dimensions in which the countries may differ, but proceed very generally, allowing for different country sizes, different welfare weights, and for different shares of high and low productivity individuals. Moreover, we again set the tax on good $x$ to zero in both countries. In the general asymmetric case we have the following result:

Proposition 2 In any equilibrium involving asymmetric countries with tax rates $t_{j, x}=t_{-j, x}=0$, both countries set $t_{j, z}=t_{-j, z}=0$. 
Proof. First, note that $t_{j, z}=t_{-j, z}=0$ is compatible with (10) and the corresponding expression $F_{-j}$. We now show that no other combination of tax rates can be an equilibrium. Observe that $t_{j, z}<0$, i.e. a subsidy on good $z$, is never an optimal policy, irrespective of the neighboring country's policy or country characteristics. If $t_{j, z}<0$ in (10), then $F_{j}>0$, contradicting condition (10). The same follows directly from $F_{-j}$ for $t_{-j, z}<0$. Consider now $t_{j, z}>t_{-j, z}$, such that $z_{-j, i, j}=0$ and $\frac{\partial z_{-j, i, j}}{\partial q_{j, z}}=0$. This implies

$$
\begin{aligned}
F_{j} & =\sum_{i=l, h} A_{j} \lambda_{j, i} t_{j, z} \frac{\partial \tilde{z}_{j, i}}{\partial q_{j, z}}-\sum_{i=l, h} A_{j} \lambda_{j, i} t_{j, z} \frac{\partial z_{j, i,-j}}{\partial q_{j, z}} \\
& =t_{j, z}\left(\sum_{i=l, h} A_{j} \lambda_{j, i} \frac{\partial \tilde{z}_{j, i}}{\partial q_{j, z}}-\sum_{i=l, h} A_{j} \lambda_{j, i} \frac{\partial z_{j, i,-j}}{\partial q_{j, z}}\right)=0,
\end{aligned}
$$

which is only fulfilled for $t_{j, z}=0$ and therefore $t_{-j, z}<0$. Since we know that neither country subsidizes $z$, an equilibrium with $t_{j, z}>t_{-j, z}$ can be ruled out. Note that the combination with $t_{j, z}$ and $t_{-j, z}$ interchanged is completely analogous, such that an equilibrium with $t_{j, z}<t_{-j, z}$ can also be ruled out in the same way by considering $F_{-j}$. Finally, $t_{j, z}=t_{-j, z}>0$ can also be ruled out as an equilibrium, since it also implies (11), which requires $t_{j, z}=0$. This proves that only $t_{j, z}=t_{-j, z}=0$ is compatible with an equilibrium.

Given that the neighboring country sets $t_{-j, z}=0$, country $j$ has nothing to gain from lowering its tax $t_{j, z}$ below zero since this would imply handing out a subsidy to foreigners. Moreover, distorting relative prices between $x$ and $z$ has an additional negative affect on welfare. This follows from the logic of the AS result. The government also has nothing to gain from increasing $t_{j, z}$ above zero. This would create cross-border shopping out of the country which implies a loss of revenues and also distorts relative prices. The optimal policy is therefore to set the tax for tradable goods to zero. Thus, in an open economy with cross-border shopping, the optimal redistributive policy does not rely on indirect taxes. 
Thus, the baseline AS result holds in the general case of open economies with cross-border shopping. Despite the possibility to attract cross-border shoppers, indirect taxes cannot increase the efficiency of the tax system, and tax rates should be equalized across goods at zero. Moreover, the irrelevance result of indirect taxation of Proposition 2 is valid independent of country size, populations structure in terms of population shares of high and low skilled, and of the utility weights assigned to high and low skilled individuals, respectively. This is in contrast to the partial equilibrium models of crossborder shopping, such as Kanbur and Keen (1993) and Nielsen (2001), where differences in country characteristics are important determinants of tax rates and flows of cross-border shoppers in the equilibrium.

\section{$5 \quad$ Equilibria with indirect taxation}

Our analysis has so far set the tax rate on non-tradable goods $t_{x}$ to zero in both countries. In practice, countries typically rely on a mix of direct and indirect taxes. The application of such a tax mix can typically be traced down to tax administration or tax evasion reasons, cf. Boadway et al. (1994), among others. In the closed economy situation, setting $t_{x}>0$ is irrelevant for the AS result, and $t_{x}=t_{z}$ can be derived as the optimal tax policy, since this is just equivalent to the corresponding increases in income taxes, such that uniform indirect taxation continues to be optimal. We now investigate, whether this remains the case with cross-border shopping.

We return to the symmetric setting of Section 3, setting $A_{j}=A_{-j}=1$, $\alpha_{j, i}=\alpha_{-j, i}=\alpha_{i}$, and $\lambda_{j, i}=\lambda_{-j, i}=\lambda_{i}$, but consider the case in which indirect taxes on the non-tradable good are positive, i.e., $t_{j, x}=t_{-j, x}=t_{x}>0$. We

focus again on a symmetric equilibrium with $t_{j, z}=t_{-j, z}=t_{z}$, and thus 
$z_{-j, i, j}=z_{j, i,-j}=0$ and $\frac{\partial z_{-j, i, j}}{\partial q_{j, z}}=\frac{\partial z_{j, i,-j}}{\partial q_{-j, z}}=0$. Expression (10) then implies

$$
t_{z}\left(\sum_{i=l, h} \frac{\lambda_{i}}{a}-\sum_{i=l, h} \lambda_{i} \frac{\partial \tilde{z}_{i}}{\partial q_{z}}\right)=t_{x} \sum_{i=l, h} \lambda_{i} \frac{\partial \tilde{x}_{i}}{\partial q_{z}} .
$$

From this we directly have our next proposition:

Proposition 3 If $t_{j, x}=t_{-j, x}=t_{x}>0$, both countries choose $t_{z}<t_{x}$ in a symmetric equilibrium.

Proof. The result follows from (12) and the fact that $\sum_{i=l, h} \frac{\lambda_{i}}{a}>0$.

Requiring $t_{x}>0$ completely changes the situation. The AS result no longer holds. Both countries have an incentive to differentiate indirect tax rates to attract cross-border shoppers. The optimal policy trades off the necessity to balance indirect taxes between goods with the competitive pressures originating from the competition for cross-border shoppers. The difference between the tax rate on the non-tradable good and the tax on the tradable good in equilibrium depends on the intensity of the tax competition. If transportation costs become very high $(a \rightarrow \infty)$ the term $\sum_{i=l, h} \frac{\lambda_{i}}{a} \rightarrow 0$ and, as evident from expression (12), rate differentiation vanishes. Proposition 3 also has welfare implications:

Corollary 4 Given any symmetric positive level of indirect taxes on nontradable goods, for both countries welfare is lower in the equilibrium than in the global, information-constrained second best.

Proof. An information-constrained social planner maximizing joint welfare of both countries would set $t_{z}=t_{x}$ in both countries, as follows directly from the $A S$ result. The equilibrium entails differentiated indirect taxes and thus a lower level of welfare.

Apparently, if indirect taxes play an important role in the tax systems of the countries under consideration, tax competition for cross-border shopping 
has the potential to lower welfare, since it induces tax differentiation which generates additional distortions without improving redistribution.

Next, we consider the possibility that only one country has an exogenous positive tax rate on the non-tradable good. This amounts to the case in which $t_{j, x}>t_{-j, x}=0$. In this case, we have the following result:

Proposition 5 If $t_{j, x}>t_{-j, x}=0$, an equilibrium must entail $t_{j, z}>t_{-j, z}>0$. Proof. If $t_{j, x}>0$ and $t_{-j, x}=0$, the expression (10) now differs between country $j$ and country $-j$. They are given as

$$
\begin{aligned}
F_{j}= & \sum_{i=l, h} A_{j} \lambda_{j, i} t_{j, z} \frac{\partial \tilde{z}_{j, i}}{\partial q_{j, z}}+\sum_{i=l, h} \lambda_{j, i} A_{j} t_{j, x} \frac{\partial \tilde{x}_{j, i}}{\partial q_{j, z}} \\
& -\sum_{i=l, h} A_{j} \lambda_{j, i} t_{j, z} \frac{\partial z_{j, i,-j}}{\partial q_{j, z}}+\sum_{i=l, h} A_{-j} \lambda_{-j, i} z_{-j, i, j}+\sum_{i=l, h} A_{-j} \lambda_{-j, i} t_{j, z} \frac{\partial z_{-j, i, j}}{\partial q_{j, z}}=0 \\
F_{-j}= & \sum_{i=l, h} A_{-j} \lambda_{-j, i} t_{-j, z} \frac{\partial \tilde{z}_{-j, i}}{\partial q_{-j, z}} \\
& -\sum_{i=l, h} A_{-j} \lambda_{-j, i} t_{-j, z} \frac{\partial z_{-j, i, j}}{\partial q_{-j, z}}+\sum_{i=l, h} A_{j} \lambda_{j, i} z_{j, i,-j}+\sum_{i=l, h} A_{j} \lambda_{j, i} t_{-j, z} \frac{\partial z_{j, i,-j}}{\partial q_{-j, z}}=0 .
\end{aligned}
$$

The following constellations are potential equilibria: $\left.i) t_{-j, z} \geqslant t_{j, z}=0, i i\right) t_{j, z}=$ $\left.\left.\left.t_{-j, z}>0, i i i\right) t_{j, z}>t_{-j, z}=0, i v\right) t_{-j, z}>t_{j, z}>0, v\right) t_{j, z}<0$, or $t_{-j, z}<$ $0, v i) t_{j, z}>t_{-j, z}>0$. Substituting these possibilities into (13) and (14) shows that vi) is the only combination compatible with the equilibrium. Given that an equilibrium exists, it entails $t_{j, z}>t_{-j, z}>0$.

Indirect taxation in one country results in rate differentiation in both countries. Moreover, the existence of indirect taxation can trigger indirect taxation in the other country, even if this country would not rely on indirect taxes in the absence of the possibility of cross border shopping.

Finally, we again consider a regulation that requires both countries to use uniform taxation in this asymmetric case. We have the following proposition: 
Proposition 6 Assume that $t_{j, x}>0$ and $t_{-j, x}=0$ for exogenous reasons. Starting from the laissez-faire equilibrium derived above with $t_{j, x}>t_{j, z}>$ $t_{-j, z}>0$, requiring both countries to set uniform taxes, such that $t_{j, x}=t_{j, z}>$ 0 and $t_{-j, x}=t_{-j, z}=0$ reduces welfare in country $-j$ and can reduce welfare in country $j$.

Proof. Consider first country $-j$. We consider the effect on its welfare in two steps. First, setting $t_{-j, z}=0$ reduces welfare, since it is not the best response. Second, increase the tax on good $z$ in country $j$ to $t_{j, z}=t_{j, x}$ has no effect on welfare, since this increases the number of cross-border shoppers, but these do not pay taxes in country $-j$. Thus the total effect on welfare in country $-j$ is negative. Consider now country $j$. Again we proceed in two steps. First, increasing $t_{j, z}$ to $t_{j, z}=t_{j, x}$, reduces welfare of country $j$, since this is a deviation from its best response. Second, the reduction of $t_{-j, z}$ to $t_{-j, z}=0$ has two effects on welfare, which both originate in the increased tax difference and the corresponding increase in cross-border shopping. On the one hand, individuals are better off, because they benefit from the lower price in country $-j$. On the other hand, the reduction in tax revenues in country $j$ reduces welfare. Unless the effect of lower prices in country $-j$ dominates the effect on tax revenues and the effect of deviating from the best response, welfare in country $j$ also decreases.

This proposition illustrates that requiring uniform taxation must not necessarily be beneficial, but will depend on the degree and nature of heterogeneity. In particular, with different exogenous tax rates, a regulation that requires countries to set uniform tax rates can reduce welfare. Note, however, that the above argument relied on $t_{-j, x}=0$, since, with positive indirect taxes, the low tax country not only has the negative effect of deviating from its best response, but also a positive effect on tax revenues. Thus, in the more general case, the effects are even less clear cut as in the examined benchmark 
case.

\section{Discussion and conclusion}

Our analysis suggests that, in general, the AS result remains valid in an open economy setting with tax competition for cross-border shoppers. Indirect taxation cannot increase the efficiency of the tax system. However, in the open economy, this result is no longer equivalent to uniform taxation at any positive rate. Tax rates only remain non-differentiated, if non-tradable goods are untaxed. If tax systems rely on positive indirect taxes the equilibrium will entail tax rate differentiation. Goods that are subject to cross-border shopping will be taxed at lower rates. This rate differentiation implies a welfare loss if both countries apply the same rate on non-tradable goods. Exogenous indirect taxes in one country are sufficient to trigger rate differentiation in both countries.

Our results are directly policy relevant for the regulation of indirect taxation in the EU. Given the importance of indirect taxes in Europe, Corollary 4 suggests that, in a world with uniform positive rates on non-tradable goods, rate differentiation for products subject to cross-border shopping should not be allowed. However, if there are differences in the rates on non-tradable goods, according to Proposition 5, these will translate into different rates on tradable goods. This tax gap, however, is smaller relative to the non-tradable goods. In such a situation, a ban of tax differentiation results the consumption distortion within countries but also leads to higher tax differences in the tradable goods and to more wasteful cross-border shopping. As indicated by Proposition 6 banning rate differentiation within countries can lead to welfare losses for both countries. Thus, if there are substantial differences in the standard indirect tax rates across Member States, a case may be made for 
leaving some scope for rate differentiation. Consequently, the more standard rates are harmonized across EU Member States, the less scope there should be for individual Member States to differentiate their rates of those goods and services that are subject to cross-border shopping. In summary, the range of products to which Member States can apply VAT rate differentiation, and the size of the deviations from the standard rates should be rather limited, and these limitations should be more restrictive, when standard rates are more harmonized between Member States. ${ }^{2}$

Our framework makes several simplifying assumptions which need to be kept in mind when drawing policy conclusions. The incentive to engage in cross-border shopping was modeled to be independent of the individual labor supply decision. This allows a proper comparison with the AS benchmark. Of course, once the labor supply decision is connected to cross-border shopping activities, additional aspects for optimal tax policy can arise. This would open an additional channel to affect incentive compatibility, and the optimal policy would additionally take these affects into account. The analysis has also made individuals completely immobile regarding their place of work, but partially mobile as consumers. In reality, mobility of workers also plays an important role for the optimal design of tax systems consisting of elements of direct and indirect taxation. Our approach is therefore complementary to studies that focus on the mobility of workers for the design of optimal direct taxation only, but do not take mobile consumers into account. An encompassing policy appraisal should also consider such additional aspects.

\footnotetext{
${ }^{2}$ Similarly, our results may be interpreted to provide support for the European limitations on individual Member States' rights to set specific excise taxes, currently in the form of minimum rates.
} 


\section{References}

[1] Agrawal, D. 2011. The Tax Gradient: Do Local Sales taxes Reduce Tax Differentials at State Borders? Paper presented at the Congress of the International Institute of Public Finance, 9 August 2011, Ann Arbor.

[2] Asplund, M., R. Friberg and F. Wilander, 2007. Demand and Distance: Evidence on Cross-border Shopping. Journal of Public Economics, 91(12), 141-157.

[3] Atkinson, A. B. and J.E. Stiglitz, 1976. The Design of Tax Structure: Direct versus Indirect Taxation. Journal of Public Economics, 6, 55-75.

[4] Boadway, R., M. Marchand and P. Pestieau, 1994.: Towards a Theory of the Direct-Indirect Tax Mix. Journal of Public Economics, 55, 71-88.

[5] Boadway, R. and P. Pestieau, 2003. Indirect Taxation and Redistribution: The Scope of the Atkinson-Stiglitz Theorem, in: Arnott, R., Greenwald, B., Kanbur, R. and Nalebuff, B. (Eds.): Economics for an Imperfect World: Essays in Honor of Joseph E. Stiglitz, MIT Press.

[6] Cremer, H., P. Pestieau and J.-C. Rochet, 2001. Direct versus Indirect Taxation: The Design of the Tax Structure Revisited. International Economic Review, 42, 781-799.

[7] Devereux, M. P., B. Lockwood and M. Redoano, 2007. Horizontal and Vertical Indirect Tax Competition: Theory and some Evidence from the USA. Journal of Public Economics, 91, 451- 479.

[8] European Commission, 2010. Green Paper on the Future of VAT: Towards a Simpler, more Robust and Efficient VAT System. COM(2010) 695 final. 
[9] Haufler, A., 1996. Tax Coordination with Different Preferences for Public Goods: Conflict or Harmony of Interest? International Tax and Public Finance 3, 5-28.

[10] Huber, B., 1999. Tax Competition and Tax Coordination in an Optimum Income Tax Model. Journal of Public Economics, 71(3), 441-458.

[11] Jacobs, J., J. Ligthart and H. Vrijburg, 2010. Consumption Tax Competition among Governments: Evidence from the United States. International Tax and Public Finance 17, 271- 294.

[12] Kanbur, R. and M. Keen, 1993. Jeux sans Frontieres: Tax Competition and Tax Coordination when Countries Differ in Size. American Economic Review, 83, 877- 892.

[13] Kaplow, L., 2006. On the Undesirability of Commodity Taxation even when Income Taxation is not Optimal. Journal of Public Economics, $90(6-7), 1235-1250$.

[14] Laroque, G. R., 2005. Indirect Taxation is Superfluous under Separability and Taste Homogeneity: A simple Proof. Economics Letters, 87, $141-144$.

[15] Lipatov, V. and A. Weichenrieder, 2010, Optimal Income Taxation with Tax Competition. CESifo Working Paper 3108.

[16] Lockwood, B. and G. Migali, 2009. Did the Single Market Cause Competition in Excise Taxes? Evidence from EU countries. Economic Journal, 119, 406-429.

[17] Naito, H., 1999. Re-Examination of Uniform Commodity Taxes under a Non-Linear Income Tax System and its Implication for Production Efficiency. Journal of Public Economics 71, 165- 188. 
[18] Nielsen, S. B., 2001. A Simple Model of Commodity Taxation and CrossBorder Shopping. Scandinavian Journal of Economics 103(4), 599- 623.

[19] Nielsen, S. B., 2002. Cross-Border Shopping from Small to Large Countries. Economics Letters, 77, 309- 313.

[20] Saez, N., 2004. Direct or Indirect Tax Instruments for Redistribution: Short Run versus Long-run. Journal of Public Economics 88, 503-518.

[21] Simula, L. and A. Trannoy, 2010. Optimal Income Tax under the Threat of Migration by Top-income Earners. Journal of Public Economics, 94(12), 163-173.

[22] Stiglitz, J. E., 1982. Self-selection and Pareto Efficient Taxation. Journal of Public Economics, 17, 213-240. 